\title{
In vitro propagation of interspecific hybrids in Alnus
}

\author{
H. Sbay, J. Guillot, P. Danthu and D. Prat
}

Laboratoire de Génétique des Populations d'Arbres Forestiers, ENGREF, 14, rue Girardet, F-54042 Nancy, France

\section{Introduction}

Alnus species show promise for afforestation and wood production, particularly on poor soils, since they are fast-growing and nitrogen-fixing trees. This allows mixed plantations with benefits to the main accompanying forest species by nitrogen supply. The genus Alnus includes some fast-growing species adapted to various ecological situations (Martin, 1985). Genetic improvement programs are being developed to produce effective clonal varieties able to grow under various ecological conditions. Controlled hybridizations (intraspecific and interspecific) were carried out to obtain improved progenies from which trees will be selected. Field trials show good performance of interspecific hybrids (Prat, 1988). The latter should be propagated to confirm their superiority and then be distributed afterwards as selected clones. In vitro micropropagation is applied because of the poor development of cuttings.

\section{Materials and Methods}

Early selection of trees (at age 4 yr) was carried out in progeny trials; 4 progenitor species were used: A. glutinosa, A. cordata, A. incana and A. rubra. The best performing and plastic hybrids (Prat, 1988) were studied: $A$. glutinosa $\times A$. incana (Gl), A. rubra $\times A$. glutinosa $(\mathrm{RG})$, $A$. cordata $\times A$. glutinosa (CG) and $A$. cordata $\times$ A. incana (Cl).

Shoots cut from selected trees were soaked in fungicide (Benlate, $0.15 \%$ ) for $24 \mathrm{~h}$ and then disinfected with calcium hypochlorite $(7 \%$ for $10 \mathrm{~min}$ ) and kept on nutritive medium containing sucrose for 1 day. Afterwards, shoots were disinfected with a mercuric chloride solution $(0.1 \%$, for $10 \mathrm{~min}$.). Nodes were separated in an anti-oxidative solution $(2.8 \mathrm{mM}$ dithiothreitol, $2.8 \mathrm{mM}$ cysteine hydrochloride, $2.8 \mathrm{mM}$ citrulline, $2.5 \mathrm{mM}$ sodium ascorbate and $0.1 \%$ polyvinyl pyrrolidone 40000 ) to avoid the browning of explants, and finally put into culture medium. Some aspects of in vitro culture were tested to improve the techniques.

\section{Results}

Basal culture medium for in vitro culture

Three media were compared for the growth of shoots: woody plant medium (WPM, Lloyd and McCown, 1980), Murashige and Skoog (1962) medium (MS), and Quoirin and Lepoivre (1977) medium (QL) supplemented with WPM micronutrient and addenda. Glucose (15 $\left.\mathrm{g}^{-1}\right)$, 
Table I. Effects of carbohydrate source on $\mathrm{Cl}$ and $\mathrm{Gl}$ clone development.

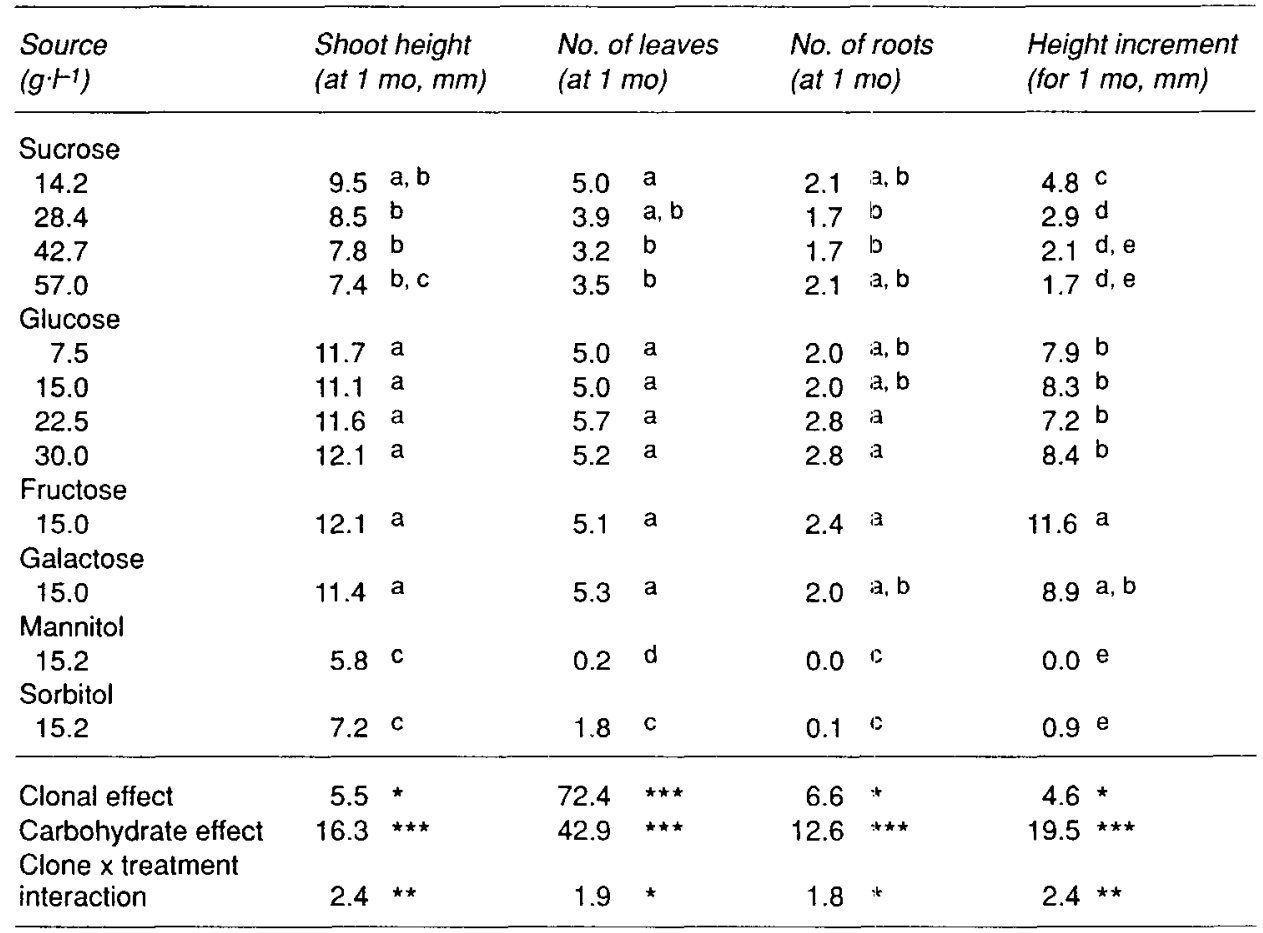

Different letters correspond to values significantly different at the $\alpha=0.05$ leve $;$;,$* * * *$; effects are significant at the $0.05,0.01$ and 0.001 levels, respectively.

indolebutyric acid (IBA, $2.5 \mu \mathrm{M}$ ) and benzylaminopurine (BAP, $2.5 \mu \mathrm{M}$ ) were added to the semi-solid media.

Each tested clone ( $\mathrm{Cl}, \mathrm{CG}$ and $\mathrm{RG}$ ) grew the best on WPM. RG clones showed the least growth. The level of IBA was reduced to $0.5 \mu \mathrm{M}$ to avoid callus formation at the explant basis. The suppression of BAP allowed multiplication by elongation.

\section{Effects of carbohydrate source}

Optimum carbohydrate source was reported by Crémiere et al. (1987) to vary by species. Two clones ( $\mathrm{Cl}$ and $\mathrm{Gl}$ ) were tested with various carbohydrate sources: sucrose, glucose, fructose, galactose, mannitol and sorbitol. Carbohydrates were added to complete WPM supplemented with IBA $(1.0 \mu \mathrm{M})$ and agar.

The most extensive growth and numbers of roots and leaves (Table I) were observed in media containing either glucose, galactose or fructose. Sucrose was not the best carbohydrate source. The height increment at the end of the experiment ( $2 \mathrm{mo}$ ) was significantly higher when the carbohydrate source was fructose. For all other characteristics, the glucose (15 $\left.\mathrm{g} \cdot\right|^{-1}$ )-containing medium was never different from the treatment inducing the best performance. Glucose $\left(\left.15 \mathrm{~g} \cdot\right|^{-1}\right)$ was thus the carbohydrate source retained, but fructose $\left(15 \mathrm{~g}^{\cdot-1}\right)$ might be also retained. 
Effects of activated charcoal

The amount of activated charcoal (resuspended after autoclaving) was tested up to $40 \mathrm{~g} \cdot \mathrm{l}^{-1}$. Shoot elongation and weight increment were stimulated by activated charcoal in the range $5-20 \mathrm{~g} \cdot \mathrm{I}^{-1}$ for both tested clones ( $\mathrm{Cl}$ and $\mathrm{Gl}$ ).

The effects of sedimentation and autoclaving of activated charcoal were also analyzed. The supernatant had no effect on the growth of shoots. The significantly largest growth and numbers of roots and leaves were observed when activated charcoal $\left(5 \mathrm{~g} \cdot \mathrm{l}^{-1}\right)$ was resuspended after autoclaving the media.

The addition of gibberellic acid $\left(\mathrm{GA}_{3}\right.$, $1.5 \mu \mathrm{M})$ to activated charcoal had no effect on shoot elongation. Without activated charcoal, $\mathrm{GA}_{3}$ caused a high death rate of explants.

\section{Acclimatization to greenhouse conditions}

Rhizogenesis of shoots was induced in vitro by IBA $(0.1-10.0 \mu \mathrm{M})$ without activated charcoal. More than $95 \%$ of the shoots from $\mathrm{Cl}$ and $\mathrm{Gl}$ clones were rooted within 2 wk.

Rooted plants were then transferred into the greenhouse on a double-layer substratum (a layer of vermiculite on a layer of fertilized peat and pine bark) allowing faster growth of progressively acclimated plants. Unrooted plants did not grow; auxin application at the time of transfer into the greenhouse did not induce enough roots.

\section{Conclusion}

Plants from in vitro multiplication were grown in the nursery and followed the same development as seedlings, without plagiotropy. Clones may be produced from interspecific selected hybrids by in vitro culture, as was previously described for pure species (Tremblay et al., 1986; Crémiere et al., 1987). GI, RG, Cl and CG clones will soon be subjected to clonal trials, prior to afforestation with selected clones.

\section{References}

Crémiere L., Sbay H. \& Prat D. (1987) In vitro culture of Alnus species. Acta Hortic. 212, 543546

Lloyd G. \& McCown B. (1980) Commerciallyfeasible micropropagation of mountain laurel (Kalmia latifolia) by use of shoot-tip culture. Proc. Int. Plant Prop. Soc. 30, 421-427

Martin B. (1985) Les aulnes. AFOCELARMEF Info. Forêt 268, 177-191

Murashige T. \& Skoog F. (1962) A revised medium for rapid growth and bioassays with tobacco tissue cultures. Physiol. Plant. 15, 473497

Prat D. (1988) Intérêt de l'hybridation interspécifique et de la multiplication végétative: le cas de l'aulne. In: Actes $2^{e}$ Colloque Sciences et Industries du Bois. Tome 1, Arbolor, Nancy, pp. 161-168

Quoirin M. \& Lepoivre P. (1977) Etude de milieux adaptés aux cultures in vitro de Prunus. Acta Hortic. 78, 437-442

Tremblay M.F., Perinet P. \& Lalonde M. (1986) Tissue culture of Alnus spp. with regard to symbioses. In: Biotechnology in Agriculture and Forestry, Trees vol. I. (Bajaj Y.P.S., ed.), Springer-Verlag, Berlin, pp. 87-100 